\title{
Future Changes in Temperature and Precipitation Extremes in the State of Rio de Janeiro (Brazil)
}

\author{
Wanderson Luiz Silva1, Claudine Dereczynski ${ }^{1}$, Sin Chan Chou $^{2}$, Iracema Cavalcanti ${ }^{2}$ \\ ${ }^{1}$ Department of Meteorology, Federal University of Rio de Janeiro, Rio de Janeiro, Brazil \\ ${ }^{2}$ Center for Weather Forecasting and Climate Research, National Institute of Space Research, Paulista, Brazil \\ Email: wanderson@ufrj.br
}

Received 16 October 2014; revised 8 November 2014; accepted 1 December 2014

Copyright (C) 2014 by authors and Scientific Research Publishing Inc.

This work is licensed under the Creative Commons Attribution International License (CC BY). http://creativecommons.org/licenses/by/4.0/

(c) (i) Open Access

\begin{abstract}
In this study, we document the air temperature and precipitation changes between present-day conditions and those projected for the period 2041-2070 in the state of Rio de Janeiro (Brazil) by means of Eta driven by HadCM3 climate model output, considering the variation among its four ensemble members. The main purpose is to support studies of vulnerability and adaptation policy to climate change. In relation to future projections of temperature extremes, the model indicates an increase in average minimum (maximum) temperature of between $+1.1^{\circ} \mathrm{C}$ and $+1.4^{\circ} \mathrm{C}\left(+1.0^{\circ} \mathrm{C}\right.$ and $+1.5^{\circ} \mathrm{C}$ ) in the state by 2070 , and it could reach maximum values of between $+2.0^{\circ} \mathrm{C}$ and $+3.5^{\circ} \mathrm{C}$ $\left(+2.5^{\circ} \mathrm{C}\right.$ and $\left.+4.5^{\circ} \mathrm{C}\right)$. The model projections also indicate that cold nights and days will be much less frequent in Rio de Janeiro by 2070, while there will be significant increases in warm nights and days. With respect to annual total rainfall, the Northern Region of Rio de Janeiro displays the greatest variation among members, indicating changes ranging from a decrease of $\mathbf{- 3 5 0} \mathbf{~ m m}$ to an increase of $+300 \mathrm{~mm}$ during the $21 \mathrm{st}$ century. The southern portion of the state has the largest increase in annual total rainfall occurring due to heavy rains, ranging from +50 to $+300 \mathrm{~mm}$ in the period 2041-2070. Consecutive dry days will increase, which indicates poorly time distributed rainfall, with increased rainfall concentrated over shorter time periods.
\end{abstract}

\section{Keywords}

Climate Change, Climatic Extremes, Future Projections, Temperature, Precipitation, Rio de Janeiro

\section{Introduction}

Climatic variations in a given region, whether natural or anthropogenic, can lead to various environmental im-

How to cite this paper: Luiz Silva, W., Dereczynski, C., Chou, S.C. and Cavalcanti, I. (2014) Future Changes in Temperature and Precipitation Extremes in the State of Rio de Janeiro (Brazil). American Journal of Climate Change, 3, 353-365. 
pacts such as elevation or reduction in mean sea level, an increase or decrease in frequency of occurrence and intensity of droughts, heavy rains, heat waves and transient systems (cyclones, frontal systems and others). The knowledge of future climate change contributes to the establishment of mitigation measures, since such impacts have consequences for areas of human concern such as agriculture, health, urban planning, and water resources, among others.

Periodic reports from the Intergovernmental Panel on Climate Change (IPCC) about the causes, impacts and measures for mitigating global climate change serve as a standard reference on this subject for the entire scientific community and for governments and industries worldwide. The Fifth Assessment Report (AR5) of the IPCC [1] indicates that the global average surface temperature may increase by $2.6^{\circ} \mathrm{C}$ to $4.8^{\circ} \mathrm{C}$, generating an increase in mean sea level of between 45 and $81 \mathrm{~cm}$, considering its most pessimistic scenario (RCP8.5). The report also shows that the contrasts in precipitation between rainy and dry regions and between rainy and dry seasons will increase, despite some regional exceptions.

The state of Rio de Janeiro's climate exhibit high variability as a result of its quite complex terrain, with hills, mountains, valleys, variety of vegetation, and lowland areas and bays, as well as the proximity to the Atlantic Ocean. In the climatological fields of the spatial distribution of air temperature and precipitation highlight the strong presence of the Paraíba Valley and of the Mountainous Region, even as the coast. In addition, the state has the highest population density in Brazil [2], making it very vulnerable to extreme weather events. [3] identified statistically significant increases in mean maximum temperature (between $+0.01^{\circ} \mathrm{C} /$ year and $+0.08^{\circ} \mathrm{C} /$ year) in the Metropolitan Region and in the North and Northwest Region of the state between 1961 and 2012. It is also presented significant rise trends in the percentage of warm nights and days in almost the entire state (between $+0.1 \%$ and $+0.6 \%$ days/year). As for rain, it is observed that there is a statistically significant upward trend in the annual rainfall totals in the Coastal Lowlands (between +4.0 and $+32.0 \mathrm{~mm} /$ year) in the same period. Also, it is verified a significant increase in rainfall totals of more heavy rains in the year in the Coastal Lowlands and in part of the Metropolitan Region, with magnitudes between +2.0 and $+20 \mathrm{~mm} /$ year.

To develop projections of future climate change, numerical general circulation models of the earth system are used. However, since global models need to cover a broad area, they are not able to represent many sub-grid scale feedback processes controlled by local features, such as high resolution of topography, land-sea boundaries, vegetation and others. Therefore, projections of future regional climate change obtained from regional models nested within global models have been used by many different research groups. At the National Institute for Space Research (INPE), the regional Eta model [4] was adapted to perform present and future climate integrations [5] [6]. Nested in the global model of the UK Met Office's Hadley Centre (HadCM3), the regional Eta model is known as the Eta-HadCM3 model. Integrations of this model with $40 \mathrm{~km}$ horizontal resolution are used in this research for the state of Rio de Janeiro.

The objective of this work is to support studies of vulnerability and adaptation to climate change scenarios in Rio de Janeiro State. In order to achieve this goal, we conducted investigations using future projections (20412070) of indicators of climatic extremes in the state, using the regional climate model Eta-HadCM3, and considering the variations among its four members (Cntrl, High, Mid and Low), as described in [5]. The results of these analyses are outlined in this article. We present the data and methodology in Section 2; the results of future model projections for temperature and precipitation in Section 3; and the conclusions and final remarks in Section 4.

\section{Data and Methodology}

\subsection{Models}

In this study, simulations of future generated by INPE's $40 \mathrm{~km}$ regional Eta climate model nested in the HadCM3 (Coupled Atmospheric-Ocean General Circulation Model) of the Hadley Center are used. Information about this model is summarized below and can be found in greater detail in [5] and in [6].

\subsubsection{Global Model (HadCM3)}

The boundary conditions for the regional Eta model are provided by the control member and three other members of the HadCM3 model [7]. Its atmosphere has a horizontal resolution of $2.5^{\circ}$ latitude $\times 3.75^{\circ}$ longitude, with 19 vertical levels [8]. The HadCM3 model has been evaluated by the Fourth Assessment Report (AR4) of the IPCC [9] for simulating the climate in Brazil [10]. 
Experiments with ensemble members provide the means by which the uncertainty in climate change projections can be partially explored. The ensemble of the HadCM3 model uses an approach in which the structure of a simple model is used with perturbations introduced into the physical parameterization schemes. This perturbed physics ensemble (PPE) is very expensive in computational terms, but is a method for systematic examination of the uncertainties in the different components of the model. This is done by first identifying the model parameters that are uncertain as well as important for the model response, and thus it becomes feasible to use an ensemble of several members to explore the implications of these uncertain parameters [11]. In addition to the standard model HadCM3, 16 variant models were run in fully coupled transient mode, forced with the IPCC Special Report Emissions Scenarios (SRES) A1B [12] generated by the concentration of $\mathrm{CO}_{2}$ at the end of the 21st century. Although each member of the ensemble is forced with the same concentrations of $\mathrm{CO}_{2}$, the effect of different combinations of parameter settings alters the degree and form of patterns of climate change. The range of uncertainty in global mean temperature at the end of the twenty-first century across all the members of the model has magnitude similar to that generated by the AR4 ensemble [11].

\subsubsection{Eta Regional Model}

The regional climate is simulated using the regional Eta model [5], which is derived from the Eta model [4] developed at the University of Belgrade (Serbia) and operationally implemented by the National Centers for Environmental Prediction-NCEP [13]. The Eta model was chosen because it has been used operationally at INPE. Moreover, the $\eta$ vertical coordinate system used in this model is appropriate for use over South American continent due to the steep slopes of the Andes.

This model has been used in studies of seasonal forecasts for South America [14], where forecasts were improved with respect to the CPTEC/INPE AGCM, which has horizontal resolution around $200 \mathrm{~km}$ (T62). The Eta model is configured with $40 \mathrm{~km}$ horizontal resolution and 38 vertical levels, with the top at $25 \mathrm{hPa}$ using the $\eta$ vertical coordinate [15]. The treatment of turbulence is based on the level 2.5 Mellor-Yamada scheme [16]; the radiative transfer model was developed by the Geophysical Fluid Dynamics Laboratory (GFDL), with longwave and short-wave radiation parameterized according to [17] and [18], respectively.

The Eta model uses the Betts-Miller scheme [19] modified by [20] to parameterize convection from shallow and deep cumulus; the cloud microphysics is parameterized using the scheme of [21]. The energy transfer processes at the earth's surface are parameterized by the NOAH scheme [22]. A more detailed description of the dynamics of the model can be found in [5].

Some modifications were made to the Eta model to adapt it to the climate change runs through the use of sea surface temperature (SST) derived from the monthly average of the HadCM3 model. The SST model updates daily by linear interpolation. The main change in the Eta model is the 360-day calendar, which was necessary in order to use the boundary conditions from HadCM3. The inclusion of a $\mathrm{CO}_{2}$ increase in the Eta model was made possible by updating the indices of absorption and transmissivity every 5 years. Changes in the original code of the Eta model were made so that the $\mathrm{CO}_{2}$ concentration could vary according to the scenarios used. At decadal time scales, linear interpolation was developed to avoid sudden jumps in the annual values generated for the amount of $\mathrm{CO}_{2}$.

\subsubsection{Integration of the Eta-HadCM3 Regional Climate Model}

As described in Section 2.1.1, the PPE's from the HadCM3 model with atmospheric forcing from the A1B greenhouse scenario consists of the standard model plus 16 ensemble members, each with a different climate sensitivity. It is expected that the large variation in the response of global temperature by the end of the 21st century also produces a wide variation in the response of the temperature of the regional climate through a dynamic regionalization (downscaling). Three members plus the control were selected to measure the degree of uncertainty in the global model, since they represent reasonably well the weather over South America. Thus, a larger possible range of regional model simulations of plausible future climate can be generated.

The sets of the boundary conditions of the HadCM3 passed to the INPE Eta model were named Cntrl, High, Mid and Low. The Cntrl member is not perturbed; The High is a member with high climate sensitivity, the Mid is a member with an average sensitivity and Low is a member with low sensitivity. The sensitivity of the unperturbed member is intermediate between that of the members of low and medium sensitivity. Although only one emission scenario (A1B) is available, the differences in sensitivity of the models can provide a representative view of plausible future climate through different emission paths. The high-sensitivity member provides poten- 
tial changes similar to those of scenarios A2 and A1FI. Likewise, the changes seen in the low-sensitivity member may provide a qualitative illustration of a low-emissions scenario, such as B1 [6].

The Eta model nested to the boundary conditions of HadCM3 is referred to as Eta-HadCM3 from now onwards. The model was run in time slice mode: for the present climate, 1961-1990, and future climates 20112040, 2041-2070 and 2071-2100. In this work, the study is done for the time interval 2041-2070. The choice of this period is due to the fact that using a too-distant future period, such as the end of the century, would be more difficult for police makers decision to grasp. Moreover, it is from the 2040s on that the trends of climate change begin to show a greater dispersion in the model simulations with the Eta-HadCM3.

Since the Eta-HadCM3 model runs are provided at intervals of 6 hours (0, 6, 12 and 18 UTC), the maximum (minimum) daily temperature is taken as the highest (lowest) value of the four outputs. Daily rainfall is taken as the total accumulated during the four intervals ending between 18 UTC of the previous day and 12 UTC of the day in question, as established by the World Meteorological Organization (WMO).

In relation to future projections, the assessment of trends as indicators of climatic extremes is based on differences between the future climate (2041-2070) and the present climate (1961-1990). Maps of mean differences of index values (minimum and maximum values among the four members) in future climate and the average of the four members for the present climate from the Eta-HadCM3 runs are generated.

The Eta model topography and the regions in the state of Rio de Janeiro are presented in Figure 1. The state capital, the city of Rio de Janeiro, is located in the Metropolitan Region.

\subsection{Indicators of Climatic Extremes}

The nine indicators of climatic extremes used in this study are presented in Table 1.

The indicators of climatic extremes listed in Table 1 are calculated from the RClimdex program [23], available on the website http://cccma.seos.uvic.ca/ETCCDMI/index.shtml.

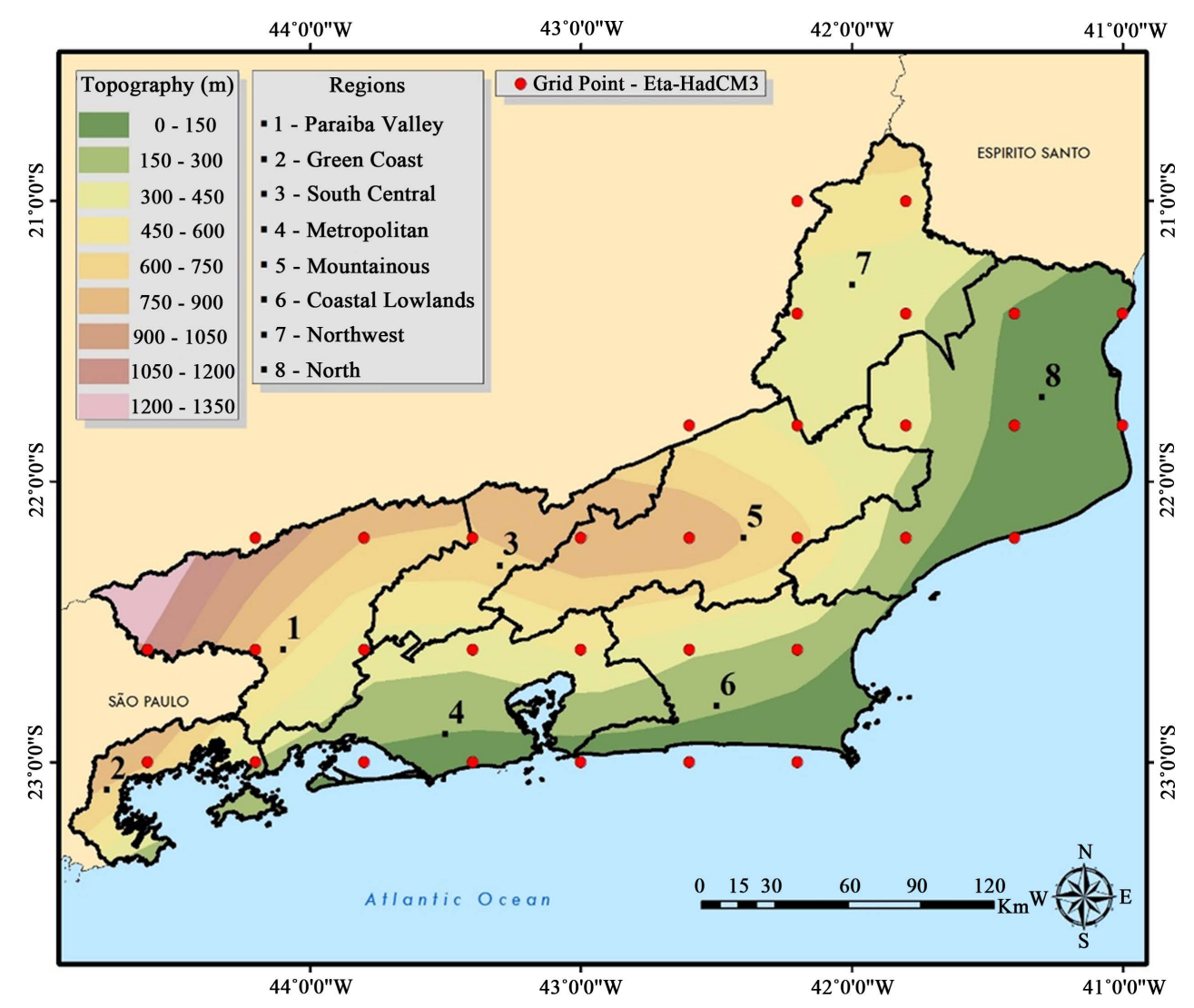

Figure 1. Model topography (m) and the 8 regions in the state of Rio de Janeiro. The red dots represent Eta model grid points. 
Table 1. Indicators of climatic extremes of minimum temperature (TN), maximum temperature (TX) and precipitation (PRCP).

\begin{tabular}{|c|c|c|}
\hline Indicator & Definition & Unit \\
\hline TMINmean & Mean annual minimum temperature & ${ }^{\circ} \mathrm{C}$ \\
\hline TN10p & Annual percentage of days for which $\mathrm{TN}<10^{\text {th }}$ percentile & $\%$ \\
\hline TN90p & Annual percentage of days for which $\mathrm{TN}>90^{\text {th }}$ percentile & $\%$ \\
\hline TMAXmean & Mean annual maximum temperature & ${ }^{\circ} \mathrm{C}$ \\
\hline TX10p & Annual percentage of days for which $\mathrm{TX}<10^{\text {th }}$ percentile & $\%$ \\
\hline TX90p & Annual percentage of days for which $\mathrm{TX}>90^{\text {th }}$ percentile & $\%$ \\
\hline PRCPTOT & Total annual precipitation & $\mathrm{mm}$ \\
\hline R95p & Total annual precipitation on days with $\mathrm{PRCP}>95^{\text {th }}$ percentile & $\mathrm{mm}$ \\
\hline CDD & Maximum number of consecutive dry days in the year (PRCP $<1 \mathrm{~mm}$ ) & days \\
\hline
\end{tabular}

\section{Results}

In this section we present the results of future projections of climate extremes indicators obtained from EtaHadCM3 simulations, based on the difference between the future (2041-2070) and present (1961-1990), considering the behavior of the four model members (Cntrl, Low, Mid and High).

The results show that future projections for the periods 2011-2040, 2041-2070 and 2071-2100 differ only in relation to the magnitudes of the differences of the indicators compared to the present climate, always keeping the same sign of increase or decrease. The analyses are performed by evaluation of the minimum and maximum values present among the four members of the model, i.e., one map with a depiction of the smallest differences and another showing the largest differences between the future (2041-2070) and present (1961-1990).

\subsection{Air Temperature}

Figure 2 shows the spatial distributions of the differences between the future (2041-2070) and present (19611990) for the indicators TMINmean and TMAXmean and their minimum and maximum values projected by the Eta-HadCM3 model. We notice that in both maps, the projections are for an increase of the minimum and maximum annual average temperatures throughout the state. According to the simulations, TMINmean should rise by at least $1.1^{\circ} \mathrm{C}$ to $1.4^{\circ} \mathrm{C}$, reaching maximum increases of between $2.0^{\circ} \mathrm{C}$ and $3.5^{\circ} \mathrm{C}$ between 2041 and 2070 . Projections are that the largest increase in the minimum temperature should occur in the central and southern portions of the state. Also according to the model, in the same period, TMAXmean should rise by less than $1.0^{\circ} \mathrm{C}$ to $1.5^{\circ} \mathrm{C}$ in the state, with increases reaching values of between $2.5^{\circ} \mathrm{C}$ and $4.5^{\circ} \mathrm{C}$, i.e., increasing at a rate higher than that of TMINmean, thereby exacerbating the urban heat islands. It is observed that the highest increases of the maximum temperature should occur in inland areas, especially in the extreme Northwest of the state.

In Figure 3 the graphs of the temporal evolution of the indicator TMINmean in the Metropolitan Region and TMAXmean in the Northern/Northwestern part of the state of Rio de Janeiro are presented. Projections indicate that TMINmean (TMAXmean) can reach $21.0^{\circ} \mathrm{C}-24.0^{\circ} \mathrm{C}\left(28.5^{\circ} \mathrm{C}-33.5^{\circ} \mathrm{C}\right)$ by the end of the century, i.e., establishing an increase of between $+2.5^{\circ} \mathrm{C}$ and $+5.5^{\circ} \mathrm{C}\left(+2.0^{\circ} \mathrm{C}\right.$ to $\left.+7.0^{\circ} \mathrm{C}\right)$ compared with the present climate, as observed in [24] and [25].

The spatial distributions of the indicators TN10p and TX10p, built along the same lines as Figure 2 are shown in Figure 4. In both maps the projections show a decrease in cold nights (TN10p) and cold days (TX10p) over the entire state of Rio de Janeiro. A decrease of between $9 \%$ and $10.0 \%$ in the number of cold nights per year is projected for the coast. The number of cold days per year decreases by between $6.5 \%$ and $10 \%$.

Figure 5 shows the spatial distributions of the indicators TN90p and TX90p, as in Figure 2. It can be seen that in both maps, the projections call for rising frequencies of warm nights (TN90p) and hot days (TX90p) throughout Rio de Janeiro, with a greater impact in the coastal areas, which are already relatively hot compared 

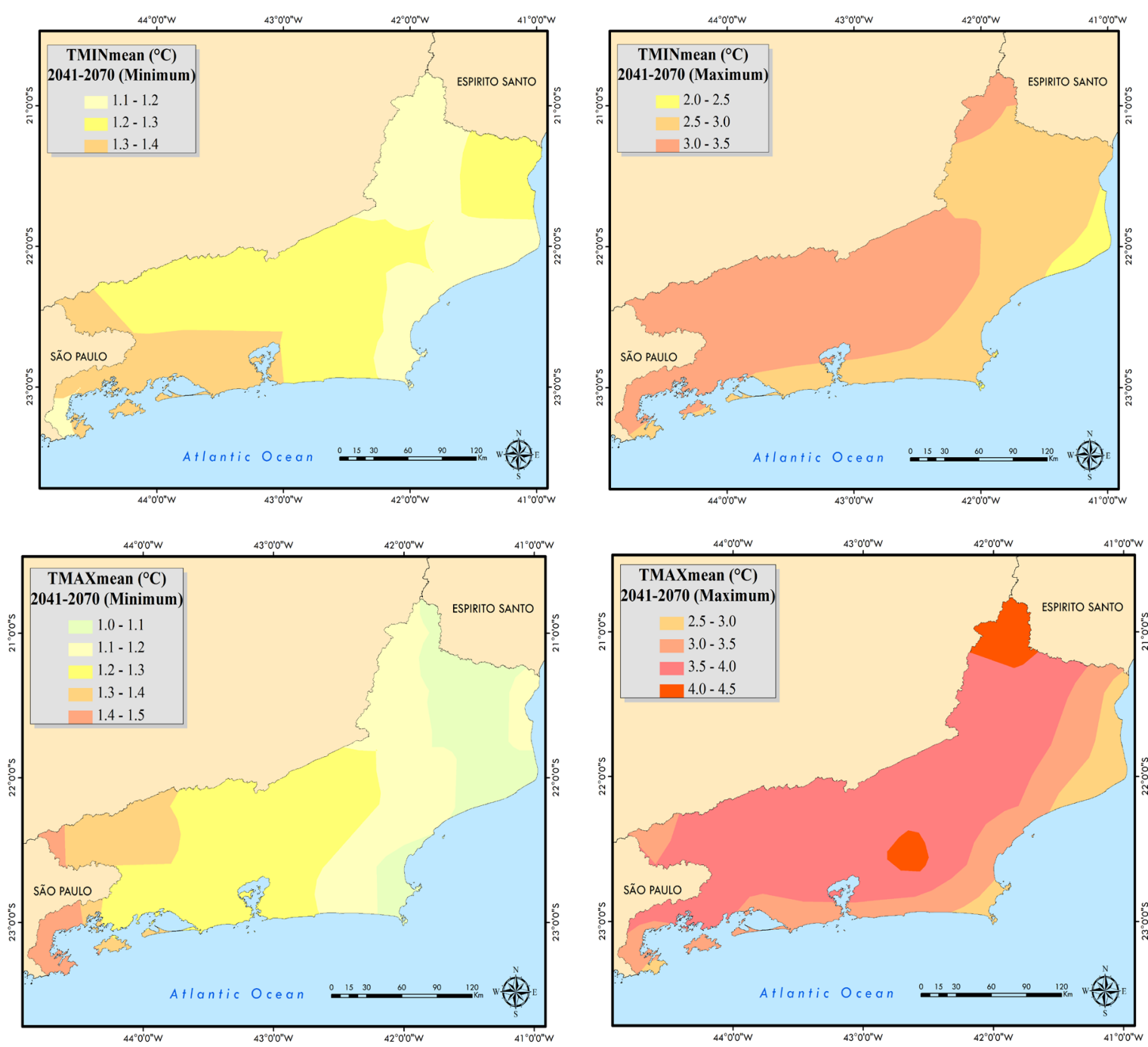

Figure 2. Minimum (left) and maximum (right) differences between the future (2041-2070) and present (1961-1990) for the indicators TMINmean (above) and TMAXmean (below) in ${ }^{\circ} \mathrm{C}$.

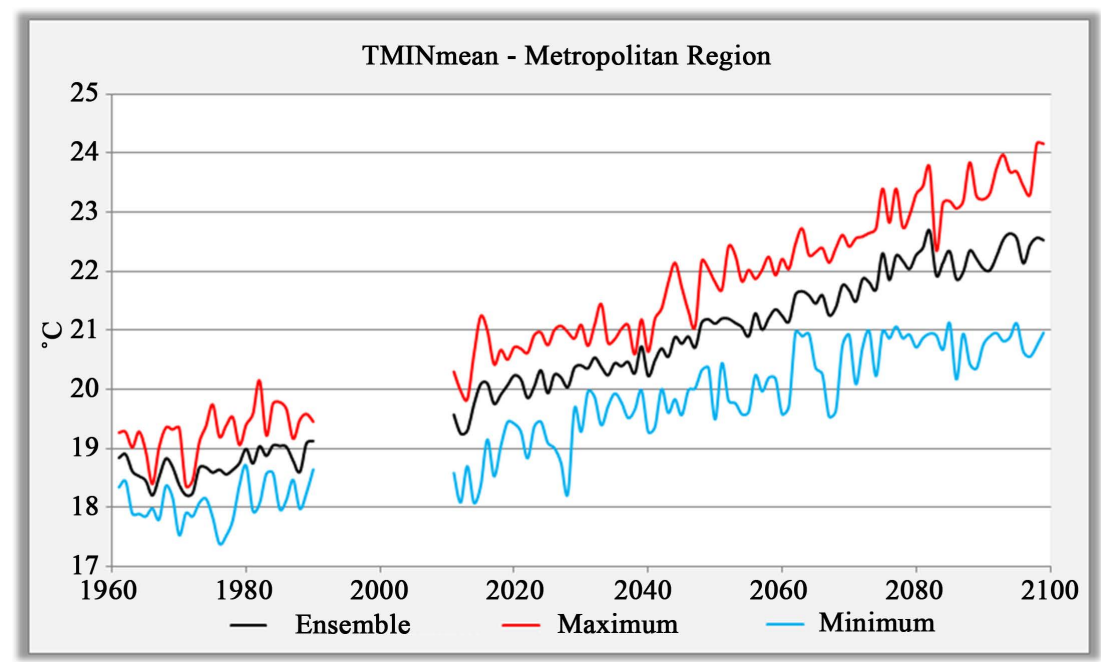

(a) 


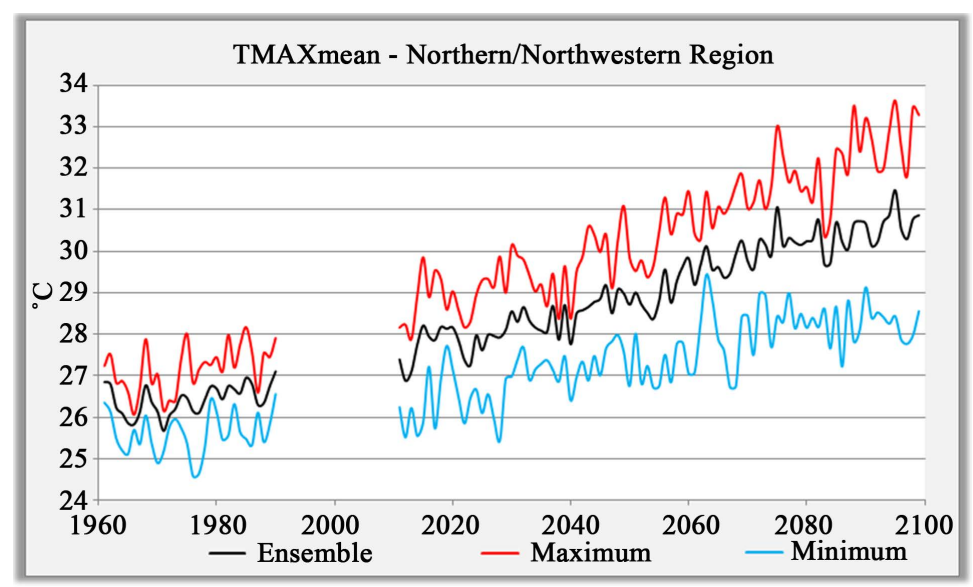

(b)

Figure 3. Evolution with time of: (a) TMINmean in the Metropolitan Region of the state of Rio de Janeiro and of (b) TMAXmean in the Northern/Northwestern Region of the state, both in ${ }^{\circ} \mathrm{C}$.
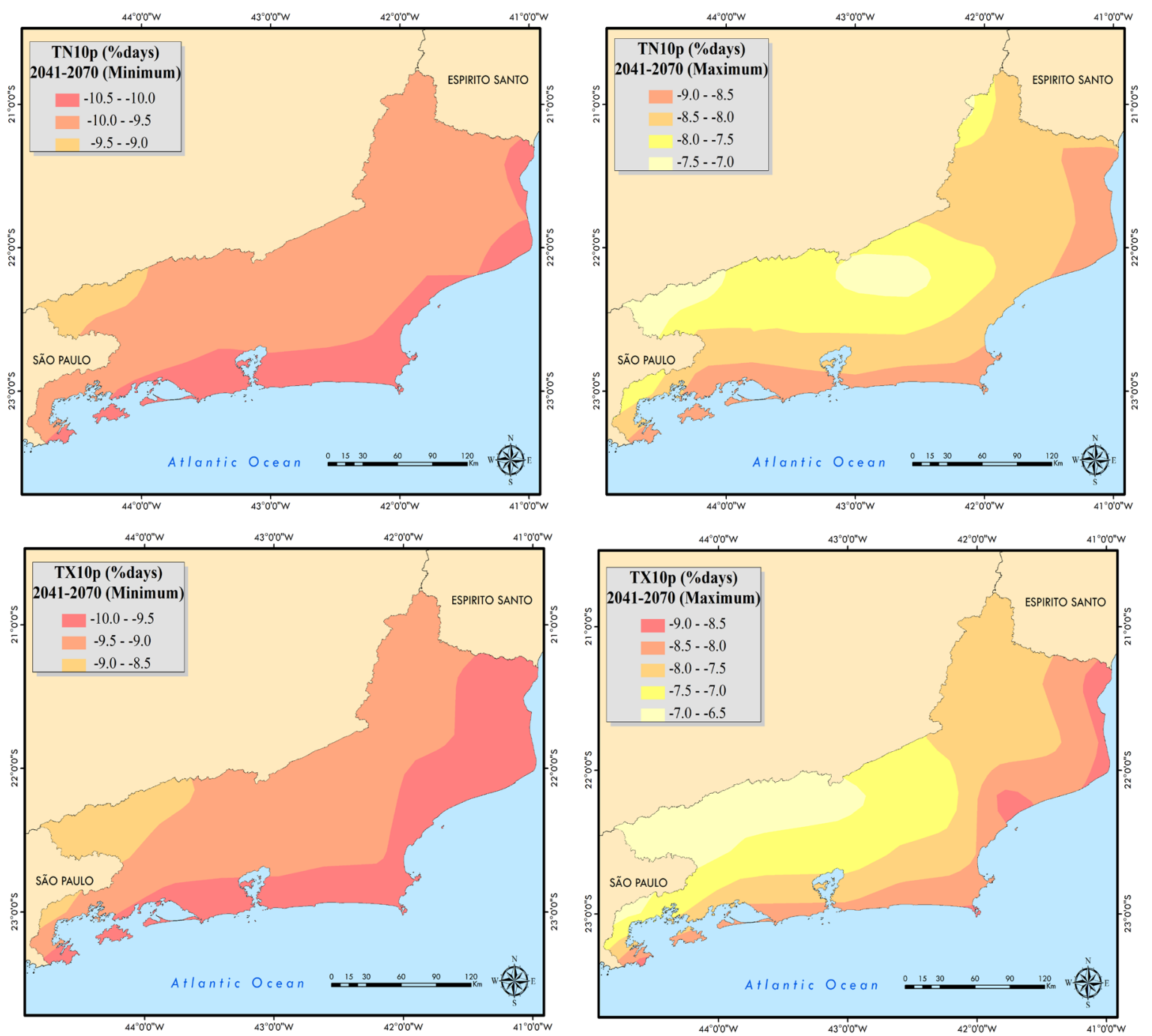

Figure 4. Minimum (left) and maximum (right) differences between the future (2041-2070) and present (1961-1990) for the indicators TN10p (above) and TX10p (below) in \% of days per year. 

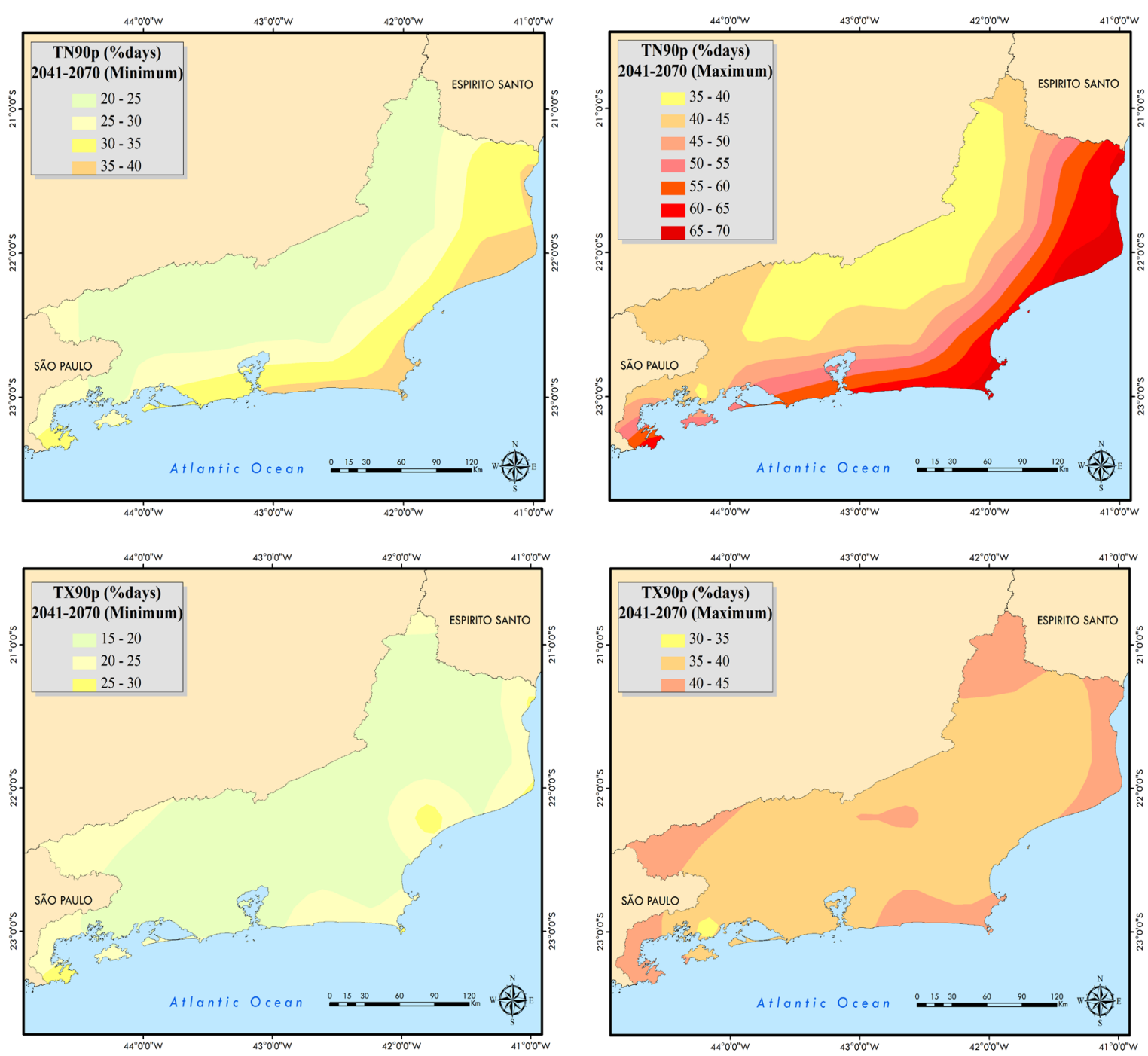

Figure 5. Minimum (left) and maximum differences (right) between the future (2041-2070) and present (1961-1990) for indicators TN90p (above) and TX90p (below) in \% of days per year.

to the rest of the state, as described in [3]. Regions such as Green Coast, Metropolitan, Northern, and the Coastal Lowlands feature increases ranging from $30 \%$ to $70 \%$ in the number of hot nights per year in the period 2041-2070. As for the number of hot days, most of the state of Rio de Janeiro presents an annual increase of 15 to $40 \%$ during this period.

Figure 6 shows the temporal evolution of TN90p on the coast and of TX90p in the Coastal Lowlands of Rio de Janeiro. An increase can be seen in TN90p (TX90p) for this region that should lies between 65\% and 95\% (40\% and $75 \%$ ) by 2100 .

\subsection{Precipitation}

The spatial distributions of the differences between the future (2041-2070) and present (1961-1990) of the indices PRCPTOT and R95p and their minimum and maximum values projected by the Eta-HadCM3 model for the state of Rio de Janeiro are shown in Figure 7. Note that the range of variation between increase and decrease of both indicators is great throughout the state. The Northern portion has the largest variation, who indicated values ranging from a decrease of PRCPTOT of $-350 \mathrm{~mm}$ to an increase of $+300 \mathrm{~mm}$. This wide range over the state may be related to the fact that meteorological variables of this type suffer considerable influence from other climatic elements and geographical factors. As for the R95p index, the southern portion of the state has the 


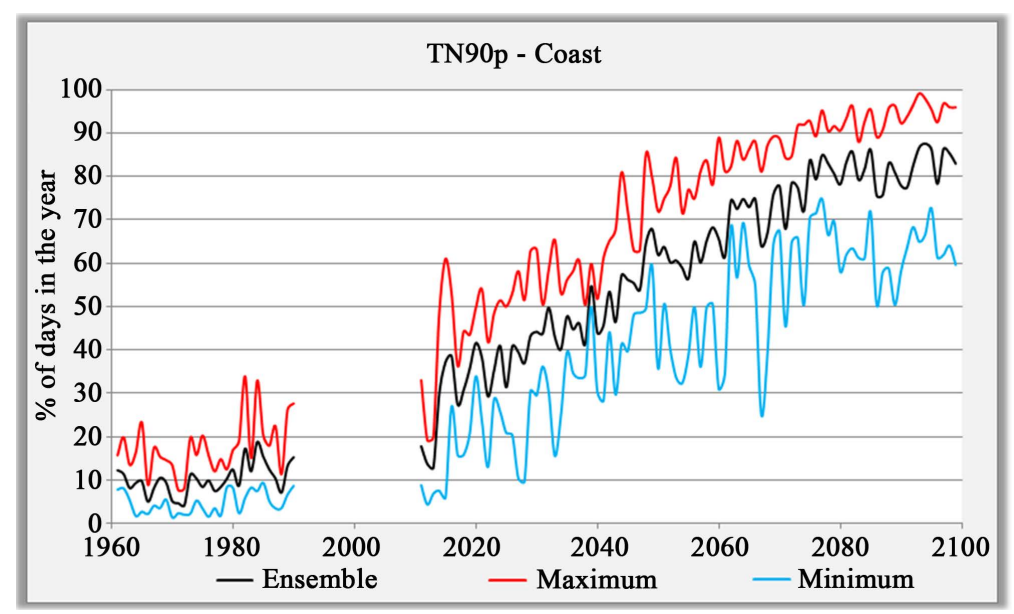

(a)

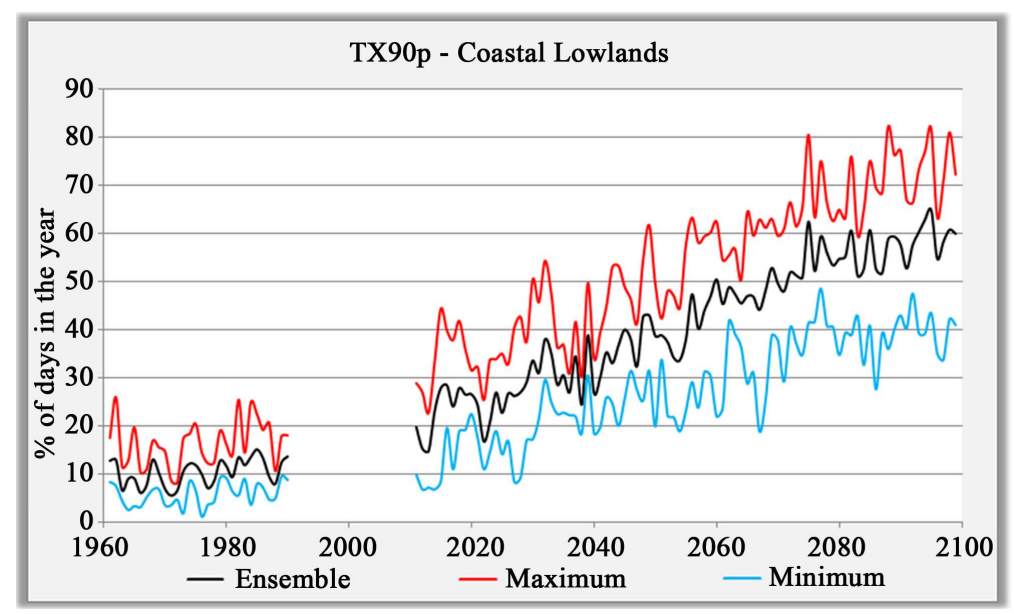

(b)

\section{Figure 6. Temporal evolution of (a) TN90p on the coast and (b) TX90p in the Coastal} Lowlands, both in \% of days per year.

highest increases in intense rainfall, with values ranging from +50 and $+300 \mathrm{~mm}$ in the period 2041-2070. It is worth remembering that this area already has high annual rainfall, especially the regions near Angra dos Reis (at Green Coast) and Resende (at Paraiba Valley) cities. In addition, the southern region of the state also has an important concentration of power plants, including thermoelectric, thermonuclear and hydroelectric, and the efficiency of the last one depending directly on accumulated rainfall totals.

Figure 8 shows the evolution with time of PRCPTOT in the Mountainous Region and of R95p in the southern region. It is observed that there can be a decrease of PRCPTOT of around $-400 \mathrm{~mm}$, as well as an increase of $+200 \mathrm{~mm}$ in the mountains by the end of the century, which in any case, will have a direct influence, especially on the agricultural production of this area. As for R95p in the south, this indicator can increase by between 300 and $650 \mathrm{~mm}$ by 2100 , which is a rather pronounced elevation compared to the present climate.

The indicator CDD is shown in Figure 9, constructed along the lines of Figure 7. It can be seen that in both maps, the projections are for an increase throughout the state in total consecutive dry days. The extreme Northern portion of the state shows the largest variation associated with periods of drought, with increases varying between 1.0 and 10 days. As mentioned above, the heavy rains tend to increase over a large part of the state at the same time that the periods of drought are projected to lengthen. Thus, it is probable that the heaviest rain events will be concentrated in shorter time periods by the end of the 21st century.

Figure 10 shows the time evolution (1961-2100) of the indicator CDD in the North and Northwest of the state. Note that the values of CDD may be between 20 and 40 days by 2100, i.e., there is a possibility that the index could stabilize over the years, just as there is the chance of doubling it over the period. 

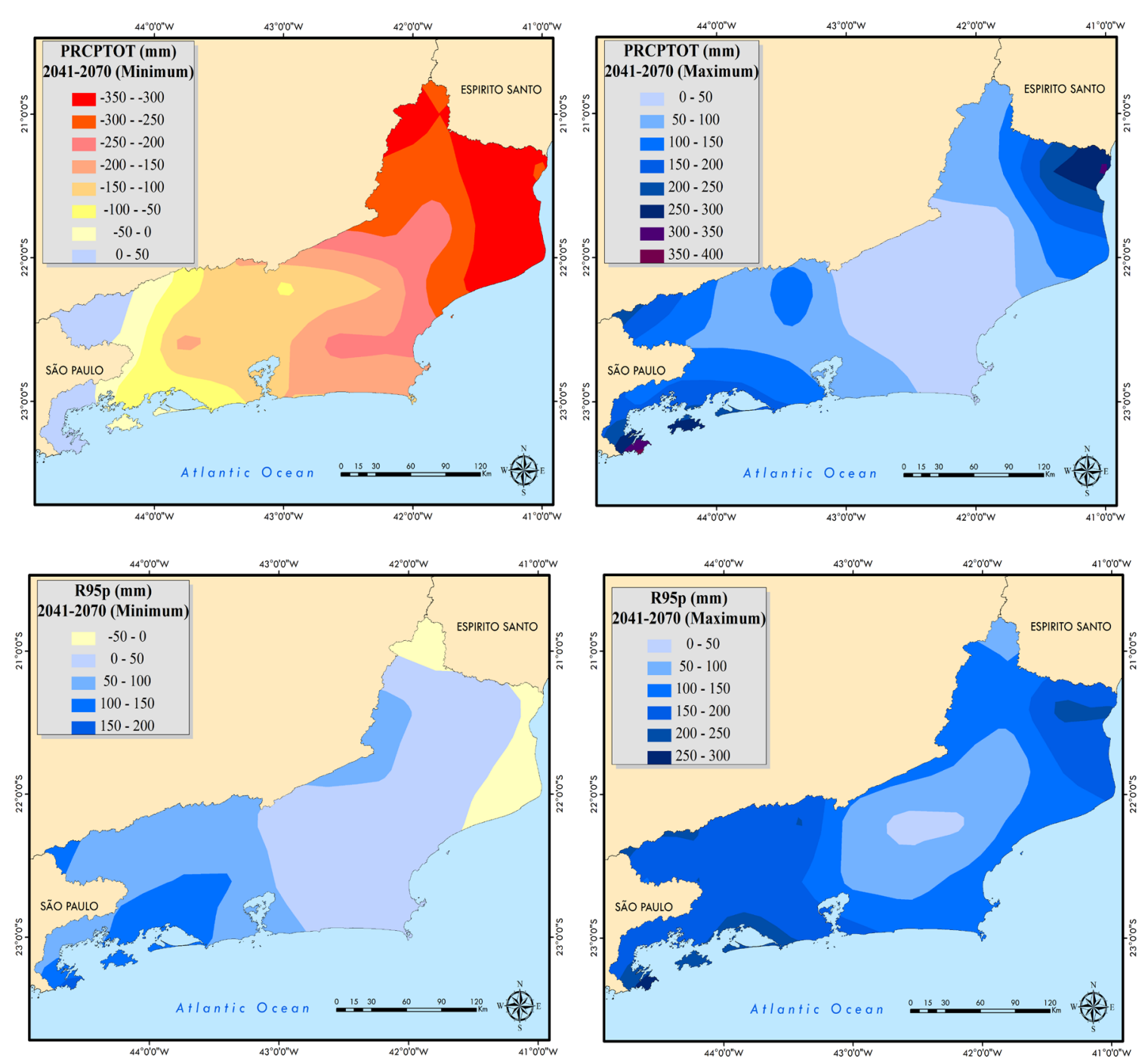

Figure 7. Minimum (left) and maximum differences (right) between the future (2041-2070) and present (1961-1990) indicators PRCPTOT (above) and R95p (below) in mm.

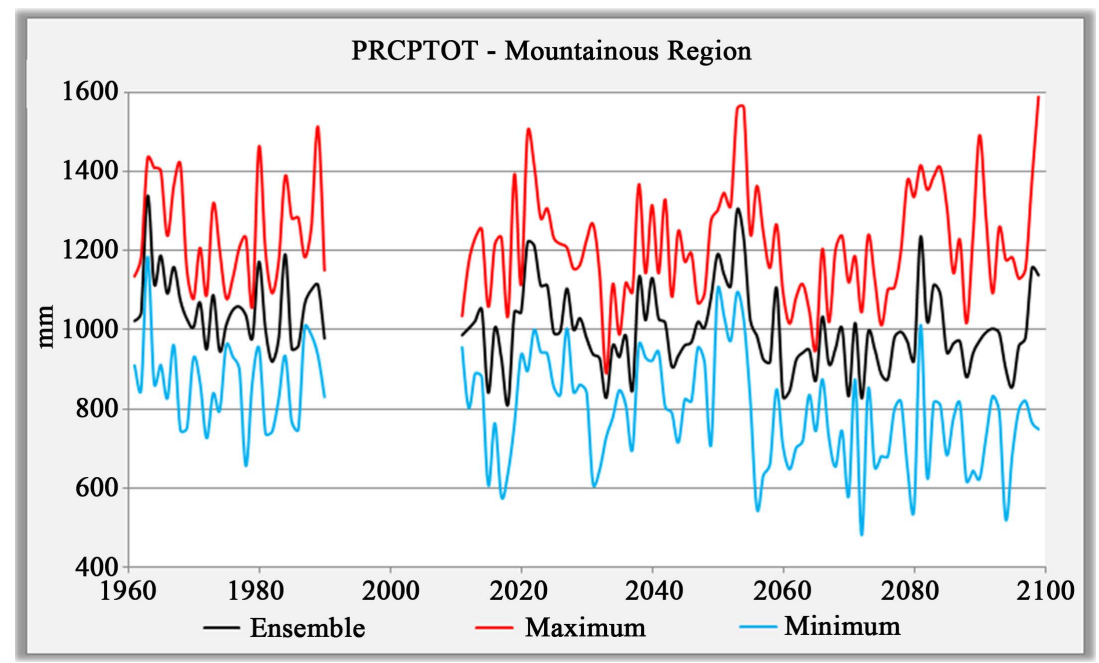

(a) 


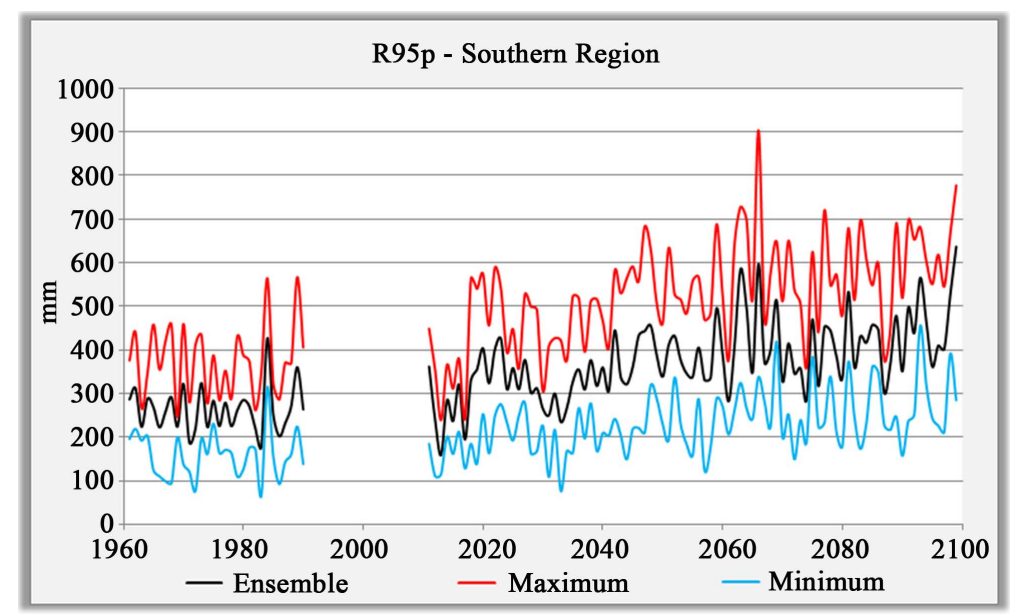

(b)

Figure 8. Time evolution of (a) PRCPTOT in the mountainous region and (b) $\mathrm{R} 95 \mathrm{p}(\mathrm{mm})$ in the southern region of the state of Rio de Janeiro, both in $\mathrm{mm}$.
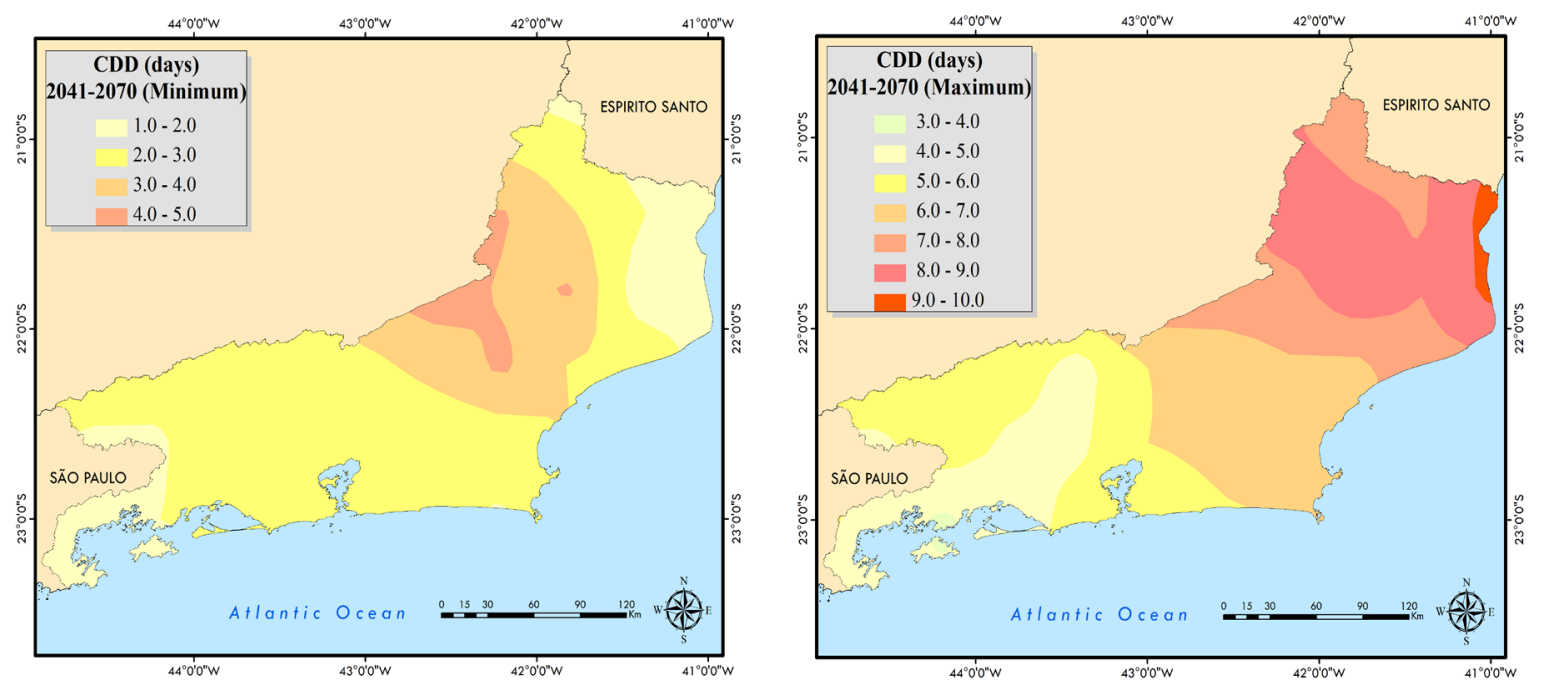

Figure 9. Minimum (left) and maximum differences (right) between the future (2041-2070) and present (1961-1990) for the indicator CDD in days.

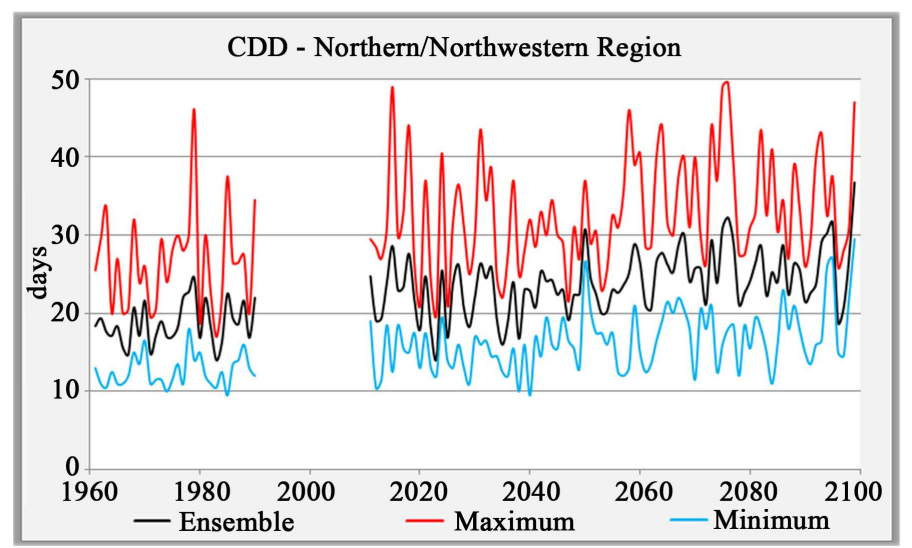

Figure 10. Values of CDD in the Northern/Northwestern region of the state of Rio de Janeiro in days. 


\section{Conclusions}

In this study, we conducted an assessment of future projections (2041-2070) of indicators of climatic extremes associated with temperature and precipitation in the state of Rio de Janeiro, using the Eta-HadCM3 regional climate simulations, considering the dispersion (uncertainty) among its four members.

In relation to future projections of climatic extremes of temperature, we note that the projections are showing an increase of the minimum and maximum annual average temperatures throughout the state of Rio de Janeiro. Note that the projections show increases in warm nights and warm days throughout the state, with a greater warming in coastal areas. Future projections of climate extremes of precipitation indicate that the range of variation between increases and decreases in the mean annual rainfall is large throughout the state of Rio de Janeiro. Note that the projections increase the total amounts associated with heavy rainfall throughout the state, with the exception of the extreme North and Northwest portions.

According to future projections, the Northern and Northwestern parts of the state of Rio de Janeiro present the greatest susceptibility to climatic extremes. In these areas, the projections of temperature increase are the highest compared with those for the rest of the state. Extremes are also present in projections of precipitation, indicating the possibility of a reduction or an increase in the total annual rainfall, as well as an increase in dry periods.

Concerning these model projections, it is important to emphasize that the simulations take into account only the increase in the concentration of greenhouse gases and not changes in land use or the heat island effect due to urban expansion. Furthermore, when it comes to the regional model, the reliability of the simulations for high resolution depends on the quality of the lateral boundary condition, which is provided by the global model, and also the actual capacity of the regional model itself to reproduce realistic regional characteristics of the present climate.

\section{Acknowledgements}

The first author would like to thank the Coordination for Improvement of Higher Education Personnel (CAPES) for supporting the study. The authors are grateful to the Foundation for Research Support of the state of São Paulo (FAPESP) for collaboration through project No. 2008/58161-1—“Assessment of Impacts and Vulnerability to Climate Change in Brazil and Strategies for Adaptation Options”.

\section{References}

[1] Stocker, T.F., Qin, D., Plattner, G.-K., Tignor, M., Allen, S.K., Boschung, J., Nauels, A., Xia, Y., Bex, V. and Midgley, P.M., Eds., Intergovernmental Panel on Climate Change-IPCC: Climate Change 2013 (2013) The Physical Science Basis-Contribution of Working Group I to the Fifth Assessment Report of the IPCC. Cambridge University Press, Cambridge, New York, 1535 p.

[2] Brazilian Institute of Geography and Statistics (2010) Database. www.ibge.gov.br

[3] Luiz Silva, W. and Dereczynski, C.P. (2014) Caracterização Climatológica e Tendências Observadas em Extremos Climáticos no Estado do Rio de Janeiro. Anuário do Instituto de Geociências, 37:2. Federal University of Rio de Janeiro, Rio de Janeiro.

[4] Mesinger, F., et al. (2012) An Upgraded Version of the Eta Model. Meteorology and Atmospheric Physics, 116, 63-79. http://dx.doi.org/10.1007/s00703-012-0182-z

[5] Chou, S.C., et al. (2012) Downscaling of South America Present Climate Driven by 4-Member HadCM3 Runs. Climate Dynamics, 38, 635-653. http://dx.doi.org/10.1007/s00382-011-1002-8

[6] Marengo, J.A., et al. (2012) Development of Regional Future Climate Change Scenarios in South America Using the Eta CPTEC/HadCM3 Climate Change Projections: Climatology and Regional Analyses for the Amazon, São Francisco and the Parana River Basins. Climate Dynamics, 38, 1829-1848. http://dx.doi.org/10.1007/s00382-011-1155-5

[7] Gordon, C., Cooper, C., Senior, C.A., Banks, H., Gregory, J.M., Johns, T.C., Mitchell, J.F.B. and Wood, R.A. (2000) Simulation of SST, Sea Ice Extents and Ocean Heat Transport in a Version of the Hadley Centre Coupled Model without Flux Adjustments. Climate Dynamics, 16, 147-168. http://dx.doi.org/10.1007/s003820050010

[8] Pope, V., Gallani, M., Rowtree, P. and Stratton, R. (2000) The Impact of New Physical Parameterizations in the Hadley Centre Climate Model. Climate Dynamics, 16, 123-146. http://dx.doi.org/10.1007/s003820050009

[9] Intergovernmental Panel on Climate Change-IPCC: Climate Change 2007 (2007) The Physical Science BasisWorking Group I Contribution to the IPCC Fourth Assessment Report. Cambridge University Press, Cambridge, New 
York.

[10] Marengo, J.A., Rusticucci, M., Penalba, O. and Renom, M. (2010) An Intercomparison of Observed and Simulated Extreme Rainfall and Temperature Events during the Last Half of the Twentieth Century: Part 2: Historical Trends. Climatic Change, 98, 509-529. http://dx.doi.org/10.1007/s10584-009-9743-7

[11] Collins, M., Booth, B.B.B., Harris, G.R., Murphy, J.M., Sexton, D.M.H. and Webb, M.J. (2006) Towards Quantifying Uncertainty in Transient Climate Change. Climate Dynamics, 27, 127-147. http://dx.doi.org/10.1007/s00382-006-0121-0

[12] Nakicenovic, N., et al. (2000) Special Report on Emissions Scenarios. Cambridge University Press, Cambridge, 599 p.

[13] Black, T.L. (1994) The New NMC Mesoscale Eta Model: Description and Forecast Examples. Weather and Forecasting, 9, 256-278.

[14] Bustamente, J., Gomes, J.L. and Chou, S.C. (2006) 5-Year Eta Model Seasonal Forecast Climatology over South America. 8th Inter Conference on Southern Hemisphere Meteorology and Oceanography, Foz do Iguaçu, 24-28 April 2006, 503-506.

[15] Mesinger, F. (1984) A Blocking Technique for Representation of Mountains in Atmospheric Models. Rivista di Meteorologia Aeronautica, 44, 195-202.

[16] Mellor, G.L. and Yamada, T. (1974) A Hierarchy of Turbulence Closure Models for Boundary Layers. Journal of Atmospheric Sciences, 31, 1791-1806. http://dx.doi.org/10.1175/1520-0469(1974)031<1791:AHOTCM>2.0.CO;2

[17] Fels, S.B. and Schwarzkopf, M.D. (1975) The Simplified Exchange Approximation: A New Method for Radiative Transfer Calculations. Journal of Atmospheric Sciences, 32, 1475-1488. http://dx.doi.org/10.1175/1520-0469(1975)032<1475:TSEAAN>2.0.CO;2

[18] Lacis, A.A. and Hansen, J.E. (1974) A Parameterization of the Absorption of Solar Radiation in Earth’s Atmosphere. Journal of Atmospheric Sciences, 31, 118-133. http://dx.doi.org/10.1175/1520-0469(1974)031<0118:APFTAO>2.0.CO;2

[19] Betts, A.K. and Miller, M.J. (1986) A New Convective Adjustment Scheme. Part II: Single Column Tests Using GATE Wave, BOMEX, ATEX and Arctic Air-Mass Data Sets. Quarterly Journal of the Royal Meteorological Society, 112, 693-709.

[20] Janjic, Z.I. (1994) The Step-Mountain Eta Coordinate Model: Further Developments of the Convection, Viscous Sublayer and Turbulence Closure Schemes. Monthly Weather Review, 122, 927-945. http://dx.doi.org/10.1175/1520-0493(1994)122<0927:TSMECM>2.0.CO;2

[21] Zhao, Q. and Carr, F.H. (1997) A Prognostic Cloud Scheme for Operational NWP Models. Monthly Weather Review, 125, 1931-1953. http://dx.doi.org/10.1175/1520-0493(1997)125<1931:APCSFO>2.0.CO;2

[22] Ek, M.B., Mitchell, K.E., Lin, Y., Rogers, E., Grunmann, P., Koren, V., Gayno, G. and Tarpley, J.D. (2003) Implementation of Noah Land Surface Advances in the National Centers for Environmental Prediction Operational Mesoscale Eta Model. Journal of Geophysical Researches: Atmospheres, 108, 8851. http://dx.doi.org/10.1029/2002JD003296

[23] Zhang, X. and Yang, F. (2004) RClimDex (1.0)_User Manual. Climate Research Branch Environment Canada Downsview, Ontario.

[24] Luiz Silva, W. (2012) Tendências Observadas e Projeções Futuras de Extremos Climáticos na Cidade do Rio de Janeiro. Monograph, Federal University of Rio de Janeiro, Rio de Janeiro.

[25] Dereczynski, C.P., Luiz Silva, W. and Marengo, J. (2013) Detection and Projections of Climate Change in Rio de Janeiro, Brazil. American Journal of Climate Change, 2, 25-33. http://dx.doi.org/10.4236/ajcc.2013.21003 
Scientific Research Publishing (SCIRP) is one of the largest Open Access journal publishers. It is currently publishing more than 200 open access, online, peer-reviewed journals covering a wide range of academic disciplines. SCIRP serves the worldwide academic communities and contributes to the progress and application of science with its publication.

Other selected journals from SCIRP are listed as below. Submit your manuscript to us via either submit@scirp.org or Online Submission Portal.
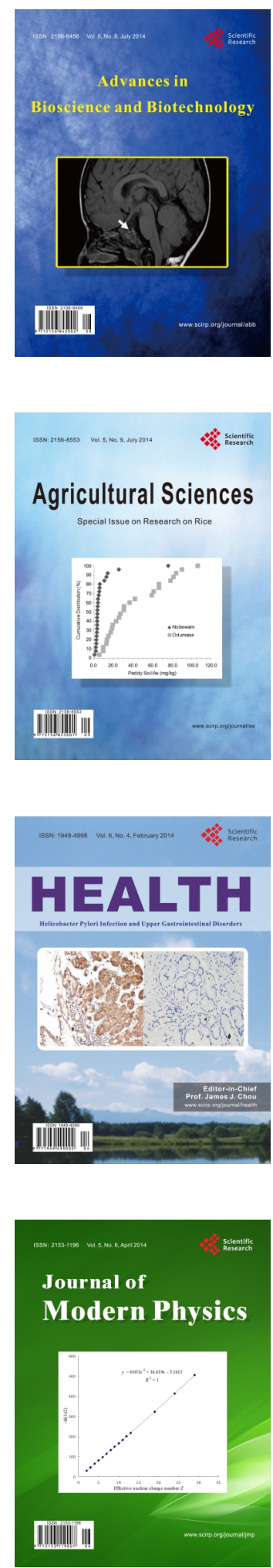
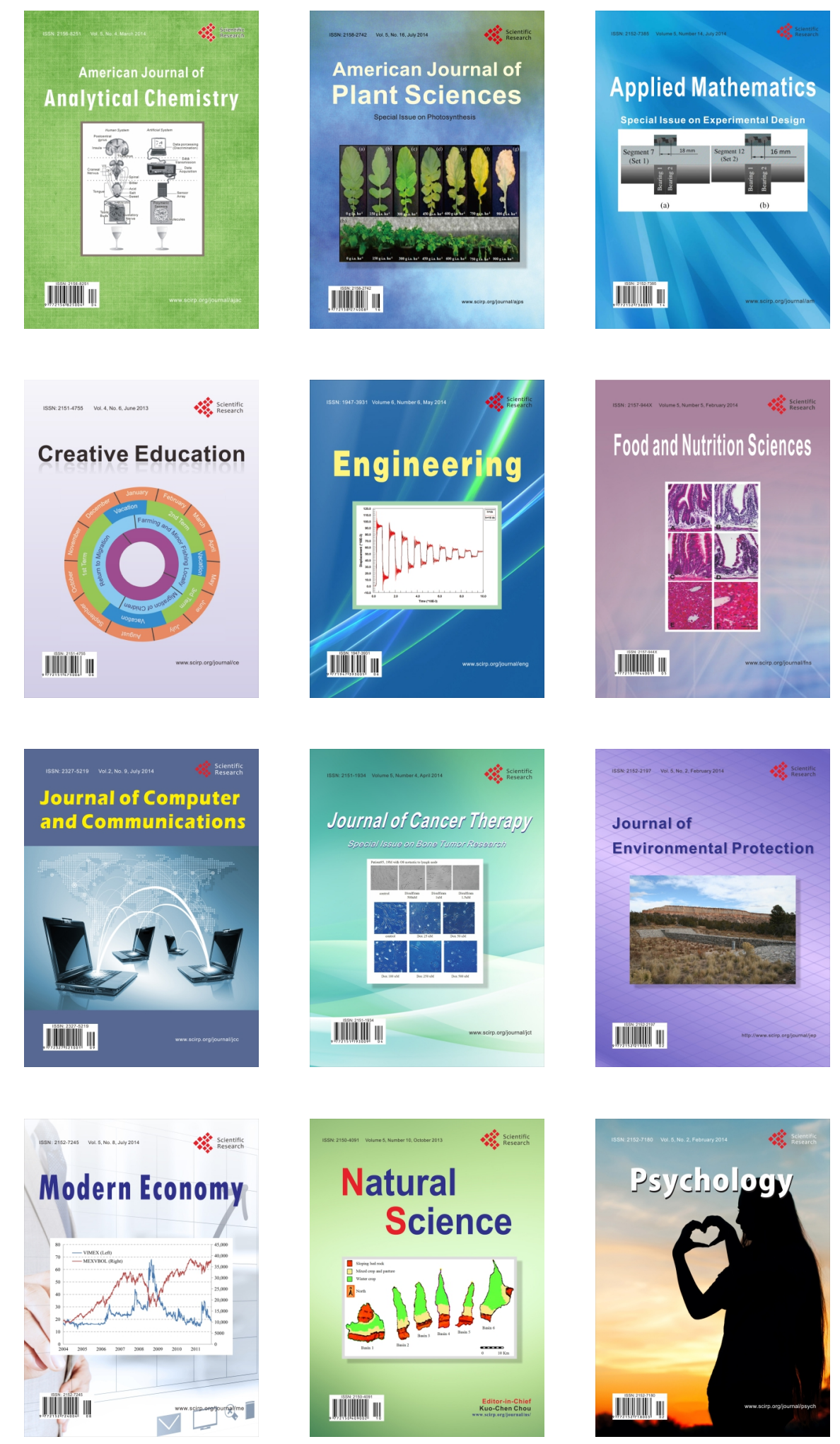